\title{
A antropologia frente às cotas raciais: notas sobre um debate entre intelectuais
}

\author{
Alexandre Plautz Lisboa ${ }^{1}$ \\ Recebido em maio de 2019 \\ Aceito em outubro de 2019
}

\section{RESUMO}

As cotas raciais no Ensino Superior brasileiro foram implementadas a partir do início da década de 2000 , mediante a ação de diferentes atores sociais, dentre eles os grupos e organizações do movimento negro, e os cientistas sociais. Neste artigo, texto síntese do meu Trabalho de Conclusão de Curso, tenho por objetivo apresentar o debate que ocorreu no campo da antropologia acerca das cotas, marcado por fortes divergências entre os pesquisadores em um momento em que cabia aos próprios docentes implementar ou não uma política de reserva de vagas em suas universidades. A partir de uma revisão bibliográfica identifiquei aqueles que mais se envolveram com a discussão, separando-os em contrários e favoráveis, para então apresentar seus principais argumentos bem como as temáticas relacionadas à questão. Apesar da discussão ter extrapolado o ambiente universitário, os textos aqui analisados restringem-se a livros e artigos acadêmicos. Na tentativa de explicar os posicionamentos conflitantes, concluo apontando que os antropólogos partilham de noções distintas acerca do significado dos conceitos de raça e racismo, além de possuírem diferentes aproximações com o movimento negro.

Palavras chave: Cotas raciais; Antropologia; Debate; Relações raciais; Democracia racial.

\section{Anthropology in the face of the racial quotas: notes on a debate between intellectuals}

\begin{abstract}
Racial quotas in Brazilian Higher Education were implemented from the early 20oos, through the action of different social actors, including black movement groups and organizations, and social scientists. In this article, a summary text of my Course Conclusion Paper, I aim to present the debate that took place in the field of anthropology about quotas, marked by strong divergences between researchers at a time when it was up to the teachers themselves to implement, or not, a university reservation policy. From a literature review I identified those who were most involved with the discussion, separating them into contrary and favorable, then present their main arguments as well as the issues related to racial quotas. Although the discussion has extrapolated the university ambience, the texts I analyze are restricted to books and academic articles. In an attempt to explain the conflicting positions, I conclude by pointing out that anthropologists share different notions about the meaning of the concepts of race and racism, and have different approaches to the black movement.
\end{abstract}

Keywords: Racial quotas; Anthropology; Debate; Race relations; Racial democracy.

${ }^{1}$ Licenciado em Ciências Sociais (Universidade Federal do Paraná), mestrando do Programa de Pós Graduação em Sociologia (UFPR) e professor de sociologia da rede básica de ensino. E-mail: alex_plautz@yahoo.com.br 
Para o bem ou para o mal, pesam sobre os estudantes de ciências sociais alguns estereótipos sobre o curso e suas finalidades. Militantes políticos, defensores dos movimentos sociais, partidários da esquerda, feministas, essas são apenas algumas das impressões que recorrentemente chegam aos nossos ouvidos sobre nós - e que são inclusive compartilhadas, ano após ano, pelos próprios calouros e veteranos nos trotes, nas piadas e nas músicas de chacota. Não foi diferente comigo.

Particularmente, antes de iniciar a graduação conheci em protestos e manifestações políticas alguns estudantes de ciências sociais, o que só reforçou meu imaginário sobre a estreita relação entre a ação política e a investigação acadêmica. Ademais, por conta de certas relações firmadas com integrantes do movimento negro curitibano, também antes da graduação, passei a ter uma nova postura e percepção sobre o racismo no Brasil. Uma das amizades havia sido justamente com uma aluna de Ciências Sociais, mulher negra e feminista, mais um motivo para imaginar a Reitoria, campus das Humanas da Universidade Federal do Paraná, como um oásis da atividade política e das lutas contra as desigualdades.

Diante disso, tamanha foi minha surpresa ao me deparar, logo no primeiro semestre do curso em uma disciplina de Antropologia, com três textos contrários à política de cotas raciais, escritos por professores de importantes universidades, defendendo alguns argumentos que, em última instância, julgava serem semelhantes aqueles presente nas discussões mais rasas e superficiais do cotidiano ${ }^{2}$. Felizmente aquela surpresa, um tanto ingênua, reconheço, construída a partir de certos estereótipos e expectativas sobre o curso, foi combustível ao longo de toda a graduação para construção do meu Trabalho de Conclusão de Curso, monografia intitulada Cotas raciais em debate: uma disputa antropológica sobre a reserva de vagas nas universidades

${ }^{2}$ Os textos fazem parte do escopo de autores considerados importantes para o debate sobre as cotas, e serão analisados mais a frente. São eles: "Política de cotas raciais, os "olhos da sociedade" e os usos da antropologia: o caso do vestibular da Universidade de Brasília (UnB) (MAIO e SANTOS, 2005); Política de cotas e o vestibular da UnB ou a marca que cria sociedades divididas (MAGGIE, 2005) e As cotas raciais nos horizontes da antropologia: tréplica a dezoito comentaristas (MAIO e SANTOS, 2005b). 
(LISBOA, 2018)3 ${ }^{3}$ apresentada como requisito parcial à obtenção do grau de Licenciado em Ciências Sociais.

Conforme fui percebendo ao longo do curso, mais do que se engajar politicamente contra as desigualdades ou um determinado problema, cabe ao estudante de ciências sociais investigar e compreender as diversas facetas da realidade social. Aqueles três textos, apesar de contrários às cotas, foram construídos mobilizando conceitos antropológicos e sociológicos, ancorados em teorias e perspectivas acadêmicas justificadas pelos autores, além de terem sido publicados em uma revista científica, de modo que os argumentos apresentados no debate não poderiam ser simplesmente menosprezados e classificados como equivados. Os textos me mostraram uma série de novas questões em torno do debate sobre as cotas, de modo que aquela política que erroneamente para mim sempre tivera defesa unânime entre os cientistas sociais (estudantes e professores) logo se revelou uma enorme e polêmica controvérsia pública - termo cunhado por Campos (2012) para descrever o debate entre os cientistas sociais.

Em busca de compreender essa controvérsia, passei a estudar o debate sobre as cotas em atividades da Iniciação Científica (IC) durante dois anos ${ }^{4}$. No primeiro ano a tarefa consistiu em um levantamento bibliográfico da produção antropológica sobre as cotas raciais dos últimos 15 anos, buscando levantar os principais argumentos, conceitos e temas da problemática, além de identificar os protagonistas da discussão.

No segundo ano, após a separação dos pesquisadores em contrários e favoráveis, passei a analisar com mais atenção seus argumentos, apresentando a especificidade e os distanciamentos entre os grupos. As perguntas que mobilizaram meus esforços durante todo o processo foram as seguintes: quais foram os antropólogos que mais se envolveram com a discussão? De que forma atuaram seja para apoiar seja para criticar a política de cotas? Quais conceitos foram por eles

3 LISBOA, Alexandre Plautz. Cotas raciais em debate: uma disputa antropológica sobre a reserva de vagas nas universidades. Monografia (Licenciatura em Ciências Sociais) - Setor de Ciências Humanas, Universidade Federal do Paraná, Curitiba, 2018.

${ }^{4} \mathrm{~A}$ monografia foi resultado principalmente desses dois anos de IC, sob orientação do professor Marcos Silva da Silveira, do departamento de antropologia, o que explica seu recorte na área. 
mobilizados? Sob quais perspectivas teóricas apoiavam-se? Qual foi o papel da antropologia na implementação das cotas?

Por fim, diante dos resultados da IC realizei uma análise crítica de dois elementos presentes na argumentação contrária às cotas: as chamadas leis racialistas e sua relação com o racismo, e o critério fenotípico como base de classificação racial. Por questões de espaço, deixo de apresentar aqui essa discussão, que merece ser melhor desenvolvida em outro momento.

Apresentada minha aproximação com objeto de investigação, tenho por objetivo neste artigo trazer de forma sintetizada as reflexões da minha monografia, que trata de uma análise acerca do debate entre antropólogas e antropólogos brasileiros sobre as cotas raciais no Ensino Superior. Prossigo com uma apresentação do contexto social e político prévio ao surgimento das cotas raciais no Brasil, que ajuda na compreensão dos elementos do debate, para em seguida apresentar, brevemente, os resultados da revisão de literatura da monografia e, finalmente, os antropólogos protagonistas do debate e seus argumentos.

\section{As transformações da luta contra o racismo}

Mesmo com uma história marcada pela escravidão, a existência do racismo no Brasil nem sempre foi consenso entre os pesquisadores brasileiros. Segundo Oracy Nogueira (2006), foi somente a partir dos resultados dos estudos patrocinados pela Organização das Nações Unidas para a Educação, Ciência e Cultura (UNESCO)5 ${ }^{5}$, após a Segunda Guerra Mundial, que os cientistas sociais brasileiros convergiram nas conclusões de suas pesquisas quanto à existência do preconceito racial no Brasil. Esse foi o momento em que pela primeira vez seus depoimentos vieram "ao encontro e em reforço ao que, com base em sua própria experiência, já proclamavam, de um modo geral, os brasileiros de cor (NOGUEIRA, 2006, p. 291).

5 Após o fim da Segunda Guerra Mundial a UNESCO convidou diferentes cientistas sociais de todo o mundo para investigarem a dinâmica das relações raciais em diferentes países, com o objetivo de encontrar soluções que colocassem um fim ao racismo. Tais estudos viriam a revelar, ao longo da década de 1960, "as tensões entre o mito da democracia racial e o "racismo à brasileira"" (MAIO e SANTOS, 2005, p. 185). 
A ideia de que no Brasil não havia racismo, de que as pessoas não se importavam com a cor ou raça em suas relações cotidianas, e de que o negro não teria barreiras raciais para ascender socialmente já fazia-se presente desde pelo menos as primeiras décadas do século XX, e por vezes era mobilizada, tanto por políticos como por intelectuais, com fins de comparação com a realidade racial de outros países, como os Estados Unidos. Neste, defendia-se, vigoravam o racismo e a segregação, mediante as Leis Jim Crow - implementadas em diversos estados do sul dos Estados Unidos e que impunham a divisão racial dos espaços públicos -, ao passo que o Brasil poderia ser descrito como uma verdadeira democracia racial, onde o negro não teria problemas de se integrar na sociedade ou de conviver com os brancos.

Vale a pena conhecer a história de um grupo de afroamericanos que fundou uma companhia de colonização e tentou obter terras brasileiras durante a política de incentivo do governo à imigração, na década de 1920, em busca de uma vida nova e tranquila longe do regime segregacionista de seu país, acreditando que o Brasil fosse uma nação sem racismo. Assim que o governo brasileiro soube que se tratavam de afroamericanos, sua vinda foi impedida (RAMOS, 1996, p. 64-65). Os motivos alegados pelas autoridades, bem como as reações de certos deputados na época contra a vinda do grupo, servem para mostrar os efeitos da ideia de democracia racial, sobretudo enquanto uma política oficial do Estado. ${ }^{6}$

Institucionalizada durante o governo Vargas e transformada em doutrina de política externa durante o regime militar (GUIMARÃES, 2016, p.97), a democracia racial passou a ser questionada e combatida pelo movimento negro a partir de outras frentes após o fim da ditadura militar. Nas décadas de 1970 e 1980 diferentes movimentos sociais se reorganizaram e passaram a pautar novas ações do Estado frente às inúmeras desigualdades que denunciavam. Alguns dos momentos importantes dessa nova agenda política, referente ao movimento negro, foram

a reintrodução do quesito censitário de autodeclaração da cor no Censo de 1980; a provisão na Constituição de 1988 (...) do crime de racismo e de reconhecimento da propriedade coletiva das terras quilombolas; a criação da Fundação Palmares, em 22 de agosto de 1988, com a finalidade de preservação

${ }^{6}$ Houve quem defendesse que o negro norte-americano traria o ódio racial para o Brasil, característico das relações entre brancos e negros daquele país (RAMOS, 1996, p. 64). 
da arte e da cultura afro-brasileiras; a transformação do quesito censitário, em 1881, para cor/raça (...) (GUIMARÃES, 2016, p. 98-99).

Sendo assim, além da intenção de criar mecanismos que punissem práticas discriminatórias, as organizações do movimento negro preocuparam-se em abrir caminhos para a construção de uma identidade e senso de pertencimento étnico-racial da população negra brasileira - daí a transformação do quesito cor para cor/raça, sendo raça uma tentativa de abarcar aspectos culturais, sociais e políticos que pudessem unir os negros enquanto grupo populacional com história e demandas próprias?

A retomada dos censos de autodeclaração serviriam futuramente para mostrar, através de dados e pesquisas produzidas a partir deles, as desigualdades sociais marcadas pela diferença racial em diversas áreas (como no acesso à educação e saúde), além de evidenciar a subrepresentatividade da população negra em certos espaços de poder, como nas próprias universidades ${ }^{8}$. Aos poucos, a partir de Guimarães (2016, p. 102), o foco no combate às discriminações raciais, por parte do movimento negro, passava para o combate às desigualdades raciais. E de que formas é possível enfrentálas? O Estado passa a ser visto como ator fundamental nesse processo, após anos de ditadura militar e sua narrativa nacional de país mestiço e avesso ao racismo.

Fernando Henrique Cardoso fora o primeiro presidente a admitir a existência do racismo e das desigualdades raciais no Brasil, comprometendo-se diante do movimento negro, na Marcha Zumbi contra o Racismo, pela Cidadania e pela Vida, em 1995, a implementar políticas públicas para revertê-las - assim, vê-se um importante momento de mudança no posicionamento oficial do governo e do Estado frente à questão. As ações afirmativas - sendo as cotas raciais um de seus tipos possíveis9 surgem como uma das medidas práticas para alterar esse quadro, passando a serem discutidas a nível governamental em 1996, quando Cardoso implementa o Grupo Interministerial de Trabalho da População Negra (GUIMARÃES, 2016, p. 102).

7 Os termos "povo negro" "população negra" "comunidade negra" aparecem também em momento posterior nessa nova relação das organizações políticas, sociais e culturais perante o Estado, a exemplo do I Programa Nacional de Direitos Humanos (BRASIL, 1996).

${ }^{8}$ Falar em comunidade, povo ou raça negra, branca, indígena, asiática não fazia sentido sob uma política de valorização da mestiçagem, da união do povo brasileiro em uma só nação, de modo que a coleta de dados étnico-raciais não fora tida como importante.

9 Sobre a diferença entre cotas raciais e ações afirmativas, e para uma história dessa política no Brasil em momento de seu nascimento, ver MOEHLECKE, 2002. 
Por último, a Conferência Mundial contra o Racismo e Intolerâncias, ocorrida em Durban em 2001, e a necessidade de se levar um posicionamento da delegação brasileira demandou discussões e reuniões que mobilizaram diversos políticos, acadêmicos e militantes, tendo sido seu desfecho considerado positivo para a adoção de ações afirmativas (MAIO e SANTOS, 2005). Estes acontecimentos são importantes não só por revelarem o contexto anterior ao surgimento das cotas no Brasil - em cujo centro encontra-se o movimento negro e seus diversos atores -, mas também porque facilitam a compreensão do posicionamento dos antropólogos no debate.

A primeira experiência de cotas raciais no Brasil foi no estado do Rio de Janeiro, a partir da Lei 3.708/o1, que previa a reserva de 40\% das vagas da Universidade do Estado do Rio de Janeiro (UERJ) e da Universidade do Norte Fluminense (UENF) a pretos e pardos (RIO DE JANEIRO, 2001), passando a funcionar no ano de 2002. Devese notar, porém, que a maioria das universidades que contam hoje com um sistema de reserva de vagas, o tiveram a partir de discussões e debates internos, em seus respectivos órgãos deliberativos, como os Conselhos Universitários, por exemplo. Em respeito à autonomia universitária, e cedendo às forças partidárias presentes na Associação Nacional dos Dirigentes das Instituições Federais de Ensino Superior (Andifes), que tinham resistência às cotas raciais ${ }^{10}$, o Partido dos Trabalhadores não chegou a enviar nos primeiros anos em que esteve no governo nenhum projeto do Executivo sobre a questão das cotas, nem o fomentou no Legislativo (GUIMARÃES, 2016, p. 104).

Assim pode-se entender o lugar da antropologia - e de maneira geral de todos os pesquisadores e pesquisadoras das universidades públicas - no debate sobre as cotas, na medida em que coube aos estudantes, técnicos e, sobretudo, professores, criarem, ou não, uma política de reserva de vagas raciais em suas universidades, nos espaços deliberativos pertinentes a questão, diante de todo esse cenário nacional e internacional em que se debatiam as formas de discriminação e racismo presentes na

${ }^{10} \mathrm{Em}$ 2012, após o STF ter julgado constitucional o modelo de cotas raciais da UnB após questionamento do Partido Democratas (DEM), a Andifes, em nota, classificou a decisão do STF como "equivocada", defendendo a exclusividade do critério de renda para a entrada na universidade, e não o racial - uma "obsessão importada". Ver: Cotas raciais, um erro. ANDIFES, 27 de abril de 2012. Acesso em 23/11/2018. Disponível em: <http://www.andifes.org.br/cotas-raciais-um-erro/> 
sociedade bem como possíveis meios para eliminá-las. Isso porque a lei que atualmente garante a política de cotas em todas as universidades federais, a Lei 12.711/12 (BRASIL, 2012), foi aprovada apenas em 2012 - 10 anos depois da primeira experiência de reserva de vagas no Brasil.

Naquele ano $70 \%$ das universidades públicas do país já contavam com algum tipo ação afirmativa (GUIMARÃES, 2016, p. 94), cujos critérios variavam de instituição para instituição. O que essa lei fez, portanto, foi padronizar os critérios para reserva de vagas, além de obrigar sua implementação nas instituições e universidades federais que ainda não contavam com algum tipo de ação afirmativa. Tal lei prevê a reserva de 50\% das vagas oferecidas por todos os institutos e universidades federais do país a candidatos que cursaram o ensino médio integralmente em escolas públicas. Ainda, metade dessas vagas são reservadas a estudantes cujas famílias recebem menos de 1,5 salário mínimo e a outra metade àqueles cujas famílias recebem mais. Finalmente, uma parte dessas vagas é reservada a candidatos negros, cujo cálculo é feito a partir da proporção dessa população no estado da universidade em questão.

Portanto, atualmente, não basta ser negro para pleitear uma vaga de cotista racial, é preciso, antes, ter cursado todo o ensino médio em uma instituição pública. Isto é, um aluno negro que cursou um único ano do ensino médio numa escola particular já está impedido de disputar uma vaga como cotista a partir da Lei 12.711/12. Tal situação permite o questionamento: seriam portanto as cotas, hoje, realmente raciais, ou estaria a dimensão da raça subordinada a questão econômica? Sem querer antecipar algumas considerações, ao fim de todo o polêmico debate ocorrido, os argumentos contrários, neste ponto, parecem ter sido vitoriosos.

\section{O debate a partir de outros olhares}

O debate acerca das cotas raciais envolvendo cientistas sociais já fora objeto de estudo de outros pesquisadores, tendo cada autor e trabalho suas particularidades de recorte e interesse. A antropóloga Ana Lúcia E. F. Valente busca identificar exatamente o papel dos antropólogos no debate sobre as cotas (VALENTE, 2006), tomando como base os comentários daqueles que participaram da seção Espaço Aberto da Revista 
Horizontes Antropológicos, volume 11, número 23" ${ }^{11}$, reservada ao debate sobre as cotas, e uma nota da Comissão de Relações Étnicas e Raciais (CRER) da Associação Brasileira de Antropologia, de maio de 2004, acerca da banca de verificação racial do processo seletivo da Universidade de Brasília (UnB).

Valente faz duras críticas aos cientistas sociais que assinam o artigo base para os demais comentários, e aos antropólogos que partilham do posicionamento contrário às cotas. Considera que em ambos os momentos houve uma má vontade antropológica na discussão das cotas raciais, e percebe:

incoerências nos posicionamentos [dos antropólogos], capazes de negar compromissos da antropologia; que se colocam na contramão de estudos realizados na interface com a educação; e não reconhecem negros como sujeitos da história, protagonistas dessa opção [pelas cotas raciais] e por ela responsáveis (VALENTE, 2006, p. 91).

A socióloga Karine Goss (2010) divide os intelectuais, sobretudo cientistas sociais, entre favoráveis e contrários às cotas, e elenca os principais temas que compõem a discussão: a questão da identidade nacional, do uso da categoria raça, a problemática do fenótipo versus genótipo e da relação entre ciência e raça. Como fonte de suas análises Goss elege artigos de opinião em jornais, falas no Senado e na Câmara além de textos em periódicos, todos de autoria daqueles que considerou os intelectuais que mais se envolveram no debate. A autora não se esquivou de apontar os protagonistas do debate, de modo que pautei-me também em seus resultados para a escolha do escopo de autores por mim analisados.

A partir de uma tipologia criada por Albert Hirschman, Goss identifica uma retórica progressista nos argumentos dos cientistas sociais favoráveis às cotas e uma retórica conservadora entre os contrários. Nesta última retórica Hirschman propõe três teses, as quais a autora demonstra estarem presentes na discussão das cotas: a tese da perversidade, a tese da futilidade e a tese da ameaça (GOSS, 2010, p. 29). Não tenho por objetivo apresentar de forma detalhada sua pesquisa, mas sua conclusão é bastante pertinente:

${ }^{11}$ A importância dessa edição da revista no debate sobre as cotas raciais entre os antropólogos ficará explícita nas próximas páginas. 
A discussão sobre a implementação de cotas no Brasil provocou uma polêmica que desafiou de forma inusitada o campo acadêmico. Daí a necessidade de compreender melhor o funcionamento desse campo e a posição dos agentes que dele fazem parte. Apesar do campo científico possuir determinado grau de autonomia, percebe-se que as questões políticas o afetam diretamente, o que se torna ainda mais evidente nas ciências sociais (GOSS, 2010, p. 43).

Por último, o sociólogo Luiz Augusto Campos (2012) toma como objeto de estudo 85 artigos de opinião sobre as cotas publicados nos jornais Folha de S. Paulo e O Globo no período de 2001 a 2007, escritos por cientistas sociais ${ }^{12}$. Campos divide os pesquisadores entre favoráveis e contrários e classifica todos os textos a partir de um conjunto de variáveis que possibilitam decodificá-los estatisticamente, separando argumento por argumento e reenglobando-os em outras categorias, para fins analíticos.

Em sua análise, as 3 justificativas favoráveis que mais aparecem são: cotas corrigem injustiças; cotas reparam erros históricos; e cotas implicam o reconhecimento da diversidade. As três contrárias são: cotas racializam a nação e potencializam conflitos; cotas rompem com a igualdade como princípio; e que o problema da desigualdade é social, e não racial (CAMPOS, 2012). Também são identificadas e discutidas algumas temáticas envoltas no debate, como a miscigenação, a identidade nacional e o impacto das leis racializadas em um regime republicano. Uma das conclusões que vale ser ressaltada é a de que

a complexidade ambivalente da realidade nacional é vista ao mesmo tempo como origem do bem e fonte do mal, que por isso mesmo demanda uma solução urgente, ao mesmo tempo em que deve ser tratada com cautela. Nesse contexto, é sobre uma divisão entre um senso de urgência e uma postura cautelosa que as divergências entre os cientistas sociais se aumentam (CAMPOS, 2012, p. 70).

A partir desses trabalhos pude não apenas conhecer os principais temas que compõem o debate sobre as cotas como também confirmar quem foram os protagonistas do debate, na medida em que Goss (2010) e Campos (2012) também chegam a conclusões bastante semelhantes, separando-os em favoráveis e contrários.

${ }^{12}$ Como cientista social o autor considerou historiadores, geógrafos e economistas, além de antropólogos, sociólogos e cientistas políticos. Vale pontuar que o tema das cotas e as polêmicas envoltas foram amplamente coberto pela mídia. 
Tive acesso aos argumentos que mais apareceram, sobretudo a partir de Campos (2012), além de conhecer interessantes envolvimentos fora dos muros acadêmicos de alguns cientistas sociais, seja pela efetivação seja pelo impedimento da implementação das cotas no Brasil. O que diferencia Lisboa (2018) desses trabalhos é que na monografia a análise restringiu-se apenas sobre textos publicados em revistas ou livros acadêmicos (tendo centralidade os comentários na Revista Horizontes Antropológicos), de autoria de pesquisadores exclusivamente da antropologia, e apenas daqueles classificados como os protagonistas do debate.

Acerca dos critérios de eleição dos protagonistas do debate, que serão apresentados abaixo, vale ressaltar a entrega do manifesto Todos têm direitos iguais na República Democrática pela antropóloga Yvonne Maggie aos então presidentes da Câmara e Senado em 29 de junho de 2006, firmando um posicionamento contrário às cotas raciais assinado por mais de 100 pessoas, grande parte acadêmicos, em momento em que voltava-se a discutir o Estatuto da Igualdade Racial no Congresso Nacional ${ }^{13}$. Junto dela estavam a socióloga Bila Sorj e o militante José Carlos Miranda, do Movimento Negro Socialista ${ }^{14}$. Cinco dias depois outro manifesto foi entregue e apresentado ao Poder Legislativo, o Manifesto em favor das cotas e do Estatuto da Igualdade Racial, escrito por dois membros do movimento negro ligados à educação, e pelo antropólogo José Jorge de Carvalho.

No que se refere ao campo de atuação acadêmico ou universitário dos protagonistas, em 2007 é publicado o livro Divisões perigosas: políticas raciais no Brasil contemporâneo, organizado por Peter Fry, Yvonne Maggie, Marcos Chor Maio, Ricardo Ventura Santos e Simone Monteiro (FRY et. al, 2007), composto por vários artigos, a maioria de opinião publicados em diferentes jornais, escrito por eles e outros pesquisadores contrários às cotas raciais e tecendo considerações sobre a problemática e temáticas correlatas. Ainda em 2005, do lado favorável, José Jorge de Carvalho publica o livro Inclusão Étnica e racial no Brasil: a questão das cotas no Ensino Superior (CARVALHO, 2005), com diversos artigos contendo argumentos em defesa das cotas,

\footnotetext{
${ }^{13}$ Conforme lembra Goss, o Estatuto da Igualdade Racial foi aprovado em 2010, após 10 anos de tramitação no Congresso Nacional, porém sem a política de cotas (GOSS, 2010, p. 26, nota 4).

14 Este é um bom momento para pontuar que nem mesmo entre o movimento negro a proposta de cotas contou, desde sempre, com ampla defesa. Ver nota 14 em Lisboa (2018, p. 39).
} 
além da íntegra da primeira proposta de reserva de vagas apresentada na Universidade de Brasília (UnB) por ele é Rita Laura Segato, ainda em 1999.

Peter Fry publica o livro A persistência da raça: ensaios antropológicos sobre o Brasil e a África austral (FRY, 2005), onde desenvolve seus argumentos acerca das diferenças entre a dinâmica racial de países como o Brasil, Moçambique e Zimbábue, e que conta com dois artigos especificamente sobre as cotas, sendo um deles escrito em conjunto com Maggie. Tanto Fry (2005) como Carvalho (2005) foram utilizados para a escrita da monografia. Tais textos foram objeto de análise para as conclusões da monografia.

Antes de apresentar os argumentos deve-se ter em mente que o grande momento da discussão entre os antropólogos deu-se a partir da publicação do artigo Política de cotas raciais, os "olhos da sociedade" e os usos da antropologia: o caso do vestibular da Universidade de Brasília (UnB), escrito pelo sociólogo Marcos Chor Maio e pelo antropólogo Ricardo Ventura Santos (MAIO; SANTOS, 2005), publicado pela revista Horizontes Antropológicos, n. 23 de janeiro-junho de 2005. Tal artigo compunha a seção Espaço Aberto da revista, que convidou pesquisadores de diferentes áreas e universidades a tecerem comentários acerca dos pontos trazidos por Maio e Santos, somando 18 comentários $^{15}$. Após isso os autores escreveram uma tréplica, que também faz parte da sessão. Pode-se dizer que este foi o primeiro momento de debate acadêmico envolvendo pesquisadores de diferentes universidades sobre as cotas e temáticas correlatas. Foi basicamente pela análise do posicionamento dos antropólogos que participaram desse debate que a monografia foi construída, além das outras referências já citadas acima.

Uma última informação importante é a de que a primeira universidade federal do país a contar com uma política de cotas raciais foi a Universidade de Brasília, em 2004, e isso graças ao envolvimento direito da antropóloga Rita Laura Segato e do antropólogo José Jorge de Carvalho, responsáveis por elaborar o primeiro projeto de

\footnotetext{
${ }^{15}$ Nas palavras dos editores "o interesse da Horizontes Antropológicos é estimular reflexões sobre as interfaces entre conhecimento científico e ação política, o papel de determinado campo disciplinar na definição de políticas públicas e suas implicações, o diálogo entre determinadas tradições disciplinares, entre outros temas abordados" (TEIXEIRA e STEIL, 2005, p. 180). Todos os antropólogos elegidos por mim como protagonistas participaram do debate.
} 
cotas, ainda em 1999. Ambos os autores, bem como os que se opunham às cotas, realizaram inúmeras entrevistas e escreveram seus argumentos em artigos na imprensa, ou seja, participaram do processo de implementação em diferentes frentes. Isso também foi levado em consideração em sua classificação como protagonistas. Segue a apresentação dos argumentos contrários.

\section{As cotas e seus potenciais perigos para o Brasil: os argumentos contrários}

Os antropólogos que protagonizaram o debate apresentando argumentos contrários às cotas raciais foram Yvonne Maggie, Peter Fry, Marcos Chor Maio ${ }^{16}$ e Ricardo Ventura Santos. No artigo que inaugura o debate na Horizontes, Maio e Santos (2005) refletem sobre o sistema de cotas raciais adotado pela UnB e, mais especificamente, sobre os mecanismos elegidos pelos responsáveis pelo vestibular para identificar candidatos que pudessem fraudar o processo - candidatos brancos que viessem a disputar as vagas reservadas aos candidatos negros. Tais mecanismos foram a análise de fotografias dos candidatos cotistas e uma banca em que aqueles que tivessem sido rejeitados na primeira etapa deveriam comparecer. Não bastassem tais mecanismos, a polêmica ficaria ainda maior devido a presença de um sociólogo e um antropólogo nessa banca, que segundo Maio e Santos seriam os responsáveis por "monitorar e balizar o processo de classificação [racial], observando se este estaria em consonância com o que seria esperado a partir das evidências geradas pelas ciências sociais em sua longa tradição de estudos sobre raça e relações raciais no Brasil (MAIO e SANTOS, 2005, p. 197). ${ }^{17}$

Diante da questão da miscigenação, como analisar quem está apto a disputar a vaga de cotista (isto é, quem é negro) e quem não está? Os critérios elegidos pela UnB

${ }^{16}$ Maio é sociólogo, porém preferi mantê-lo na análise devido ao seu forte envolvimento com a ala contrária seja na publicação conjunta de artigos e livros, seja pelo seu papel, junto de Ricardo Ventura Santos, nos rumos do debate antropológico.

${ }_{17}$ Cabe pontuar que esse entendimento sobre o papel dos cientistas sociais na banca da UnB é exclusivo dos autores do artigo bem como dos que se manifestaram contrários às cotas, tendo sido questionado não somente pelos antropólogos favoráveis às cotas aqui analisados, como por outros pesquisadores que participaram da Sessão Aberta. Ver comentários de LIMA, 2005 e ANJOS, 2005 na Horizontes. A própria UnB nunca justificou a presença dos cientistas sociais na banca sob este argumento. 
foram os fenotípicos (cor da pele, textura do cabelo, etc.), e não os de ascendência (como ter parentes ou antepassados negros). A partir disso, Maio e Santos atribuíram aos cientistas sociais daquela banca o papel de buscar critérios objetivos de definição racial, como se estivessem fazendo uma antropologia das raças característica do final do século XIX, o que abriu espaço para discussões sobre a relação entre a ciência, os saberes e práticas antropológicas, as políticas de Estado e as relações raciais. Grande parte da discussão girou, portanto, em torno da polêmica construída em cima das bancas, e não sobre a urgência ou não das cotas, sobre possíveis mecanismos de eliminar o racismo e as desigualdades raciais.

O significado do conceito de raça foi outro ponto da discussão. Maio e Santos negam a ideia de que existem raças humanas - branca, negra, indígena - defendendo a existência apenas da raça humana - que não deve ser dividida e classificada sobretudo a partir de características que eles chamam de biológicas - leia-se fenotípicas. Para eles,

\begin{abstract}
os geneticistas ${ }^{18}$ colocam de forma incisiva que, no plano científico, a genética de populações constitui-se em um campo revestido da competência e autoridade para tratar da questão racial. Contudo, menos que atuar no sentido de reforçar a validação, é uma autoridade que esvazia as bases conceituais [do conceito de raça], uma vez que enfatiza que "raça" é um conceito que, do ponto de vista biológico, não se aplica à espécie humana (Maio e Santos, 2005, p. 205).
\end{abstract}

Dada a enorme miscigenação e consequente variabilidade genética identificada entre a população brasileira, e atribuindo aos estudos genéticos a legitimidade científica sobre o conceito de raça, os autores concluem que "os geneticistas secundarizam cientificamente quaisquer tentativas de classificação racial ou de definição de critérios de afro-descendência (biológica) através da morfologia" (MAIO e SANTOS, 2005, p. 205.), entendendo por morfologia os traços externos das pessoas, os fenótipos - exatamente o critério escolhido pela UnB. Ou seja, a banca, para eles, além de desrespeitar o princípio da autodeclaração, fazia um trabalho anti-científico, sendo classificada como um tribunal racial.

${ }^{18}$ A presença de geneticistas e seus comentários na Seção Espaço Aberto da Horizontes Antropológicos merecem uma melhor atenção, que foi dada, em parte, no terceiro capítulo de Lisboa (2018), mas que exige um outro momento para ser melhor desenvolvida. 
Em seu comentário Maggie (2005) também mostra-se preocupada com o que seria o fim da autodeclaração e com o papel dos cientistas sociais na banca, porém para ela o problema já estava em marcha anos antes, quando exigiu-se dos possíveis candidatos às cotas no vestibular das universidades estaduais do Rio de Janeiro, em 2002, que se autodeclarassem negros ou pardos sob penas da lei. Tal exigência significaria a entronização da raça em nosso país (MAGGIE, 2005, p.287), cuja história republicana jamais fora marcada por leis pautadas em raças, capazes de dividir a população brasileira em grupos estanques.

As cotas raciais, portanto, opor-se-iam ao sistema de classificação racial presente no Brasil, que é híbrido, flexível, flutuante, em que os brasileiros não sentem a necessidade de, ou até mesmo estranham, se classificar enquanto branco ou negro ${ }^{19}$ preferindo uma miríade de termos dos mais diversos, como mulato, moreno, caboclo, lembrados por Peter Fry (2005b, p. 171). Seriam um ponto controverso na dinâmica das relações raciais, demandariam por parte do candidato a abdicação do pertencimento à raça humana em prol da raça branca, negra, indígena, etc. Operariam uma verdadeira reclassificação racial no país. Nas palavras de Maggie,

ou você é contra a ideia de "raça" e concorda que pertence à raça humana, ou você concorda que raças existem. Se elas existem e algumas são mais discriminadas que outras e merecem ou fazer jus, ou como justiça, há que se criar uma política especial para elas (MAGGIE, 2005, p.289-290).

A dinâmica da sociedade em que as pessoas podem transitar entre marcas ou até mesmo se pensar fora delas, característica do Brasil e defendida por Maggie e por Fry, foi resultado, para a autora, do modernismo, que "com todas as suas imperfeições lutou pela instituição de um outro paradigma no qual a "raça" não marcava indelevelmente os indivíduos (MAGGIE, 2005, p. 288). Peter Fry é quem elabora de forma mais detalhada esta dinâmica, e é concebendo-a enquanto positiva que constroi seus argumentos contrários às cotas raciais. Seu comentário na Horizontes é curto

19 Para defender tal argumento a autora relata o incômodo e estranhamento de estudantes de uma escola pública do Rio de Janeiro diante de uma questão em um formulário que pedia que eles se auto classificarem em alguma das categorias do Censo Demográfico: branco, preto, pardo, amarelo, indígena (Maggie, 2005, p. 287). 
(FRY, 2005b), mas a partir do livro $A$ persistência da raça $(2005)^{20}$ é possível compreender melhor as bases de posicionamento.

Tendo morado e lecionado em diferentes países da África e sendo pesquisador das relações raciais, saltou aos olhos de Peter Fry a singularidade do Brasil quando aqui chegou, terra cujas fronteiras de sexo, de tempo, lei, raça eram imprecisas, uma "sociedade em que a miscigenação tem sido intensa e na qual tem se desenvolvido uma taxonomia "racial" que, segundo um estudo, contém pelo menos 135 categorias $^{21}$ (FRY, 2005, p. 50). Seriam essas as categorias "apagadas" ou suprimidas pela política de cotas raciais, já que esta parte de uma lógica binária de classificação racial, incompatível com o estilo múltiplo característico do Brasil (FRY, 2005, p. 194). O estilo binário é encontrado nos Estados Unidos e também em países africanos colonizados pelos ingleses, como o Zimbábue e a África do Sul, onde brancos e negros (ou africanos e ingleses) não convivem nos mesmos espaços sociais, seja em escolas, restaurantes, bairros - lembremos da África do Sul e a política do apartheid.

Nem segregados como a população do Zimbábue, mas nem tão assimilados como os moçambicanos (cuja história perpassa pela colonização portuguesa), os brasileiros desenvolveram "uma concatenação sui generis de tipos físicos e de formas culturais que é orgulhosamente exibida como a característica definidora da nação brasileira: a "democracia racial"." (FRY, 2005, p. 51). Fry diz ter ficado surpreso com a relativa homogeneidade cultural no Brasil e com a presença de símbolos africanos como símbolos da identidade nacional: "a herança africana não era apenas dos descendentes dos africanos, era de todo o Brasil (FRY, 2005, p. 27). Assim a política de cotas para os antropólogos que a contestaram representaria um risco ao Brasil, por incorporar essa lógica binária 'brancos-negros' cujos efeitos foram de dominação de intensificação das desigualdades nesses países. Por considerarem a crença em raças condição necessária para a existência do racismo (FRY e MAGGIE, 2004, p. 161), as cotas acarretariam no fortalecimento do racismo, pois consolidariam e institucionalizariam a crença em raças.

${ }^{20}$ O livro, composto de 11 capítulos, versa sobre diversas temáticas como da identidade nacional, das relações raciais em países de colonização inglesa e portuguesa, sendo os dois últimos capítulos especificamente sobre as cotas raciais, um deles escrito junto de Maggie.

${ }^{21}$ Mulato, moreno, moreno claro, moreno escuro, caboclo, etc... 
Assim, pode-se resumir os argumentos contrários às cotas nos seguintes pontos: a noção de raça é propulsora dos preconceitos raciais; o brasileiro não sente-se confortável em classificar a si e aos outros a partir da ideia de raça; o Estado brasileiro iria romper com sua história legislativa pós-república a-racial; definir quem é negro e quem não é é tarefa praticamente impossível no Brasil miscigenado; critérios fenotípicos de classificação racial são racistas e remontam a uma antropologia das raças.

\section{As cotas como forma de combate ao racismo: os argumentos favoráveis}

Só é possível entender o dissenso acerca das cotas raciais levando em consideração o diálogo entre as argumentações, e não tomando-as separadamente (CAMPOS, 2012, p. 61). Partindo disso e levando em consideração o contexto bastante delicado sobre o qual o debate dentro da antropologia fora posto pelos pesquisadores contrários, sobretudo na Horizontes, a argumentação de José Jorge de Carvalho e Rita Laura Segato assenta-se e contrapõem-se aos muitos pontos trazidos por Maio e Santos (2005) e compartilhados por Maggie e Fry.

Segato e Carvalho questionam o suposto papel do antropólogo perito racial na banca da UnB, ressaltando que no modelo de cotas elaborado por eles jamais fora proposta uma função como aquela. Na defesa pelas cotas Carvalho frequentemente faz um convite a todos os membros de sua área para reflexão acerca do perfil racial de suas instituições, e do papel de cada um no combate ao racismo, diante da baixa presença de pesquisadores negros nos programas de pós-graduação (CARVALHO, 2005, p. 237). Não é possível uma postura neutra por parte dos pesquisadores quanto a necessidade ou não das cotas, de modo que se ancorar em saberes revestidos pelo manto da ciência, sob o pretexto de neutralidade, descaracteriza a dimensão propriamente ética e política da política de cotas como uma forma de combater o racismo e suas consequências em nossa sociedade.

Para ele, a crítica às fotos "toma a implantação das cotas pelo final"(CARVALHO, 2005b, p.239), tendo sido esse mecanismo de combate aos possíveis fraudadores uma escolha de estudantes negros do Coletivo EnegreSer, envolvidos com 
a implementação das cotas na UnB desde o início de sua discussão ${ }^{22}$. A luta do coletivo, para Carvalho, demanda introduzir o protagonismo negro no processo da implementação das cotas "não apenas "fora", como "movimento social", mas também como ator dentro das universidades" (Ibid, p. 243), dimensão que segundo ele fora desconsiderada por Maio e Santos.

Segato aponta para a enorme disparidade da reação da comunidade antropológica sobre a possibilidade de se definir critérios raciais objetivos, frente a reação das lideranças negras: os antropólogos foram os que mais se sentiram ofendidos é afetados por por ela (SEGATO, 2005, p. 279). A autora questiona a origem "dessa pressa súbita desses antropólogos de oferecer aos negros brasileiros sua proteção perante os males de um sistema de cotas que lhes abrira as portas da educação superior" (SEGATO, 2005, p. 279).

Um ponto bastante importante em seus comentários na Horizontes diz respeito a história das cotas raciais na $\mathrm{UnB}$, ponto que, segundo Segato e Carvalho, não fora devidamente considerado por Maio e Santos. Trata-se de um episódio de conflito racial chamado de Caso Ari, que tem como centro Arivaldo Lima Alves, o primeiro doutorando negro do programa da UnB. Em 1998, logo no primeiro semestre do curso, Arivaldo foi reprovado numa disciplina obrigatória que o impediria de prosseguir seus estudos. Considerando a aprovação como injusta o estudante - com o apoio de José Jorge de Carvalho, seu orientador, e Rita Segato, coordenadora do Programa na época foi às últimas instâncias da universidade para reverter sua nota, fato que ocorreu em 200o, quando o Conselho de Ensino, Pesquisa e Extensão (Cepe) forçou o departamento a corrigir a nota e aprová-lo na disciplina (CARVALHO, 2005, p. 239240).

Portanto, seria em resposta a exatamente esse episódio - que causou fortes atritos no departamento, já que a maioria dos colegas, segundo Carvalho, posicionouse contra ele e seu orientando - que ele e Segato apresentaram uma proposta de cotas raciais para a instituição, ainda no ano de 1999. Nas palavras de Segato, "foi essa luta, de baixo pra cima, detonada por um caso ocorrido em 1998 e formalizada com a

${ }^{22}$ A ONG Educafro, fortemente envolvida com o debate e implementação das cotas raciais, também defendeu a comissão e seus métodos. 
primeira apresentação oficial da nossa proposta [de cotas] em 1999, que levou as cotas ao debate interno da universidade e ao debate nacional." (SEGATO, 2005, p. 276).

O desfecho dessa história é bastante significado, porém este configura como mais um dentre vários casos de discriminação racial nas universidades ${ }^{23}$. Segundo Carvalho, o pensamento que os levou a redigir a proposta foi o seguinte, referindo-se a Arivaldo Lima: "se é tão difícil manter um único aluno negro na UnB, vamos propor um sistema de cotas, para que pelo menos alguns negros permaneçam." (CARVALHO, 2005b, p. 240).

Em relação à problemática dos fenótipos e dos genótipos, e sobre o significado do conceito de raça, Segato afasta a ascendência ou a quantidade e tipos de genes como critério para definir os sujeitos da política de cotas, apontando para a peculiaridade da dinâmica das relações raciais no Brasil. Para ela

o racismo à brasileira fala disto: de que determinados signos fenotípicos tomam seu significado de uma história de guerra, escravidão, e já neste século, sistemática exclusão, e que o que importam desses signos é somente seu impacto visual num código de leitura intensamente influenciado por essa história (SEGATO, 2005, p. 68).

O problema reside, portanto, não exatamente sobre os fenótipos, mas sim nos diferentes, e hierarquizantes, significados e valores a eles atribuídos, social e culturalmente. É como se o racismo limitasse a significação positiva dos fenótipos negros, associando a eles apenas valores negativos. A política de cotas raciais teria o potencial de transformar as bases da dinâmica racial e de nossas leituras desses signos, na medida em que mais alunos negros poderiam se formar e assumir posições de prestígio na sociedade com seu diploma ${ }^{24}$. Para Segato

a pele negra é um signo ausente do texto visual geralmente associado ao poder, à autoridade e ao prestígio. A introdução desse signo modificará

${ }_{23}$ Segundo Carvalho "narrar minuciosamente exaustivamente os incidentes de discriminação racial é o único modo de de gerar um clima de discussão que estimule a formulação de propostas concretas de inclusão dos negros no meio acadêmico brasileiro." (CARVALHO, 2005, p. 87). Alguns incidentes são brevemente descritos nas páginas 85 e 86 da referência desta nota

${ }^{24}$ Já na primeira proposta, de 1999, as cotas foram apresentadas por Segato e Carvalho como "uma medida emergencial destinada a acelerar a formação de uma elite acadêmica negra capaz de contribuir com a formulação de novas políticas públicas que visem eliminar definitivamente o problema da desigualdade e da exclusão racial no Brasil" (CARVALHO, 2005, p. 46, grifos meus) 
gradualmente a forma como olhamos e lemos a paisagem humana nos ambientes em que transitamos (SEGATO, 2006, p. 86).

Outro argumento favorável às cotas leva em conta o perfil racial das universidades brasileiras, que a despeito do grande contingente populacional negro do país, contavam com um uma maioria esmagadora branca, tanto entre os discentes quanto os docentes. Em levantamento realizado à época por Carvalho em 13 universidades federais, a média de professores negros nas instituições foi de menos de 1\% (CARVALHO, 2005, p. 93-94). Vale lembrar a demanda do movimento negro pela retomada dos censos de autodeclaração nos diferentes órgãos e instituições, tendo sido a UFBA a primeira universidade a acumular dados sistemáticos do perfil étnico-racial dos calouros, no ano de $1998^{25}$ (Ibid p. 67).

Outros dados utilizados para embasar a defesa pelas cotas são aqueles de instituições como o IPEA. Após mais de 70 anos de censo, ao cruzar o marcador racial com indicadores como de renda, classe, emprego, escolaridade e região, pesquisadores concluíram que, no Brasil, pretos e pardos estão em desvantagem frente aos brancos, configurando a condição racial um privilégio para estes e uma desvantagem e exclusão para aqueles (CARVALHO, 2005, p. 26). Nos dados de 2001 e 2002, dos 25 milhões de brasileiros que viviam abaixo da linha da pobreza, 70\% eram negros. Dos 58 milhões de brasileiros vivendo na pobreza, 63\% eram negros (Ibid, p. 27).

Por último, Carvalho lembra da própria história das universidades brasileiras, criada por e para uma elite branca. Nem mesmo renomados cientistas sociais negros, que tinham como objeto de reflexão as relações raciais, conseguiram espaço enquanto professores no Ensino Superior, apesar de almejarem tal posto. Carvalho cita três casos, o de Guerreiro Ramos, Édison Carneiro e Clóvis Moura, e conclui que "o fato de que eles não puderam participar da história da nossa vida universitária deve ser lido como uma ação negativa, entendida como uma reação à possibilidade de uma integração do negro em cargos de prestígio social e econômico no país." (CARVALHO, 2005, p. 92).

${ }^{25} \mathrm{O}$ pedido fora feito à Reitoria da UFBA pela pesquisadora Delcele Queiroz, que passou a estudar o perfil social e racial dos estudantes de outras universidades. A retomada deu-se não sem certa resistência por parte da administração, afinal, não estaria a pesquisadora “estimulando" conflitos raciais? (CARVALHO, 2005, p. 67) 
Diante disso, os argumentos dos favoráveis no debate são os seguintes: as universidades apresentam um baixo número de estudantes e professores negros; os indicadores sócio-econômicos demonstram a desigualdade racial em diferentes instâncias da realidade social; a ausência de reflexão e, principalmente, ação por parte das universidades frente a esse racismo; os casos contínuos de discriminação racial nos espaços acadêmicos; a possibilidade de transformação da leitura dos signos negros, tão associados a valores negativos.

\section{Considerações finais}

A análise sobre o debate acerca das cotas raciais no ensino superior revelou profundos antagonismos entre os antropólogos, que atuaram em diferentes frentes seja para efetivar, seja para impedir a implementação da reserva de vagas. Não é porque são todos antropólogos e pesquisadores de temáticas étnico-raciais que partilham de posições semelhantes, conforme eu pensava ao entrar no curso, como se fosse tarefa ou vantagem da disciplina criar uma fórmula pronta para a diminuição das múltiplas desigualdades. Isso porque a discussão sobre as cotas é, antes de tudo, uma discussão política, resultado de um embate entre diferentes atores, sendo os antropólogos apenas um deles. A relação entre ciência e militância constitui um objeto complexo e por vezes polêmico.

Nota-se uma interpretação distinta do significado de racismo: para os favoráveis ele é percebido pelo baixo número de estudantes e professores negros nas universidades ou em postos de trabalho de alto prestígio; nos atos cotidianos de discriminação racial; na ausência do debate racial dentro da academia; na história de exclusão racial que marca a criação das universidades; no mal estar e na dificuldade dos brasileiros em discutir sobre esse passado e sobre os diferentes grupos raciais que compõem a população.

Entre os contrários, racismo pode significar o próprio uso da categoria raça em políticas públicas; na escolha dos fenótipos como critério de classificação racial; e também, é claro, os atos de discriminação racial cotidianos, porém sem tomá-los como centrais em suas discussões. Sua preocupação quanto à divisão racial do Brasil e suas 
consequências nefastas está inscrita em um âmbito mais especulativo do que concreto. Por vezes os autores acreditam que políticas universalistas, de cunho econômico, dariam conta de resolver as desigualdades entre brancos e negros, e parecem não separar exatamente o problema étnico racial do problema econômico, de classes ${ }^{26}$.

Outra conclusão diz respeito a aproximação distinta dos grupos com o movimento negro: os favoráveis o consideram ator protagonista da decisão pelas cotas, agindo inúmeras vezes em conjunto pela implementação das cotas, enquanto que essa aproximação é muito mais tímida entre os contrários, que assumem, inclusive, que seus posicionamentos podem "atrair a ira dos militantes negros" (FRY, 2005, p. 317).

Os antropólogos contrários dão valor à ausência de leis pautadas em raças na história legislativa do Brasil republicano, como também à incorporação de elementos da cultura afro no processo de construção da identidade nacional. Mas e os casos de discriminação racial? Estes não são ignorados pelos contrários, que a partir deles admitem a existência do preconceito racial no Brasil, mas devido a esses pontos por eles valorizados, paradoxalmente não consideram o Brasil um país racista (MAGGIE, 2008, p. 37).

Como apontado, a política de cotas que atualmente vigora em nosso país não toma o critério racial como o mais importante, ou o principal, na hora de se definir os sujeitos das cotas raciais. Talvez a Lei 12.711/12 só tenha sido aprovada exatamente por isso, na medida falar em raças, racismo e desigualdades raciais em nossa sociedade continua a gerar certos incômodos entre algumas pessoas. Nas escolas, o dia da consciência negra continua sendo questionado em prol da consciência humana, dificultando o debate sobre as diferenças - que não precisam resultar em desigualdades. Contudo, deve-se levar em conta que passados mais de 15 anos do auge do debate sobre as cotas, ainda não foi possível enxergar os grandes acirramentos raciais que as cotas proporcionariam, segundo o grupo contrário, mas exemplos de estudantes negros exitosos em seus projetos acadêmicos - muitos sendo os primeiros de suas famílias a ingressarem numa universidade - estão cada vez mais numerosos.

${ }^{26}$ Tome-se como exemplo a seguinte passagem de Maggie no debate da Horizontes: "Quem são os fraudadores [das cotas raciais]? São os que utilizam o sistema brasileiro de identificação racial? Quem é mais discriminado? Aquele de pais ricos que tem a pele negra ou o que tem a pele clara e os pais pobres e nem tão pretos?" (MAGGIE, 2005, p. 288) 


\section{Referências}

ANJOS, José Carlos Gomes. O tribunal dos tribunais: onde se julgam aqueles que julgam raças. Horizontes Antropológicos, vol. 11, n. 23, Porto Alegre, 2005.

BRASIL, Ministério da Justiça. Programa Nacional de Direitos Humanos. Brasília, 1996.

BRASIL. Presidência da República. Lei n. 12.711, de 29 de agosto de 2012. Dispõe sobre o ingresso nas universidades federais e nas instituições federais de ensino técnico de nível médio e dá outras providências. Diário Oficial da União, Brasília, 30 de agosto, 2012.

CAMPOS, Luiz Augusto. "We have a dream": cientistas sociais e a controvérsia sobre as cotas raciais na imprensa. Revista de Sociologia e Política, vol. 20, n. 41, Curitiba, Feb. 2012.

CARVALHO, José Jorge. Inclusão Étnica e racial no Brasil: a questão das cotas no ensino superior. São Paulo: Attar Editorial, 2005.

CARVALHO, José Jorge. Usos e abusos da antropologia em um contexto de tensão racial: o caso das cotas para negros na UnB. Horizontes Antropológicos, vol. 11, n. 23, Porto Alegre, 2005b.

FRY, Peter; MAGGIE, Yvonne. Cotas raciais - construindo um país dividido? Econômica: Revista da Pós-Graduação em Economia da UFF. Niterói, v. 6, n. 1, jun. 2004 .

FRY, Peter. A persistência da raça: ensaios antropológicos sobre o Brasil e a África austral. Rio de Janeiro: Civilização Brasileira, 2005.

FRY, Peter. Ossos do ofício. Horizontes Antropológicos, vol. 11, n. 23. Porto Alegre, 2005b.

FRY, Peter; MAGGIE, Yvonne; MAIO, Marcos Chor; MONTEIRO, Simone; SANTOS, Ricardo Ventura. (Orgs). Divisões perigosas: políticas raciais no Brasil contemporâneo. Rio de Janeiro: Civilização Brasileira, 2007.

GUIMARÃES, Antonio Sergio Alfredo. As cotas nas universidades públicas 20 anos depois. In: ARTES, Amélia; UNBEHAUM, Sandra. SILVÉRIO, Valter (Org). Ações afirmativas no Brasil: reflexões e desafios para a pós-graduação. Vol. 2. São Paulo: Cortez: Fundação Carlos Chagas, 2016. 
GOSS, Karine Pereira. O debate intelectual sobre as ações afirmativas para estudantes negros no Brasil. Revista de Ciências Sociais Política \& Trabalho, Paraíba, no. 33, out 2010 .

LIMA, Márcia. Ser negro no Brasil: do ônus ao bônus? Horizontes Antropológicos, vol. 11, n. 23, Porto Alegre, 2005.

LISBOA, Alexandre Plautz. Cotas raciais em debate: uma disputa antropológica sobre a reserva de vagas nas universidades. Monografia (Licenciatura em Ciências Sociais) - Setor de Ciências Humanas, Universidade Federal do Paraná, Curitiba, 2018.

MAGGIE, Yvonne. Política de cotas e o vestibular da UnB ou a marca que cria sociedades divididas. Horizontes Antropológicos, vol. 11, n. 23, Porto Alegre, 2005.

MAGGIE, Yvonne. Anti-racismo contra leis raciais. Interesse Nacional, vol. 1, 2008.

MAIO, Marcos Chor; SANTOS, Ricardo Ventura. Política de cotas raciais, os "olhos da sociedade" e os usos da antropologia: o caso do vestibular da Universidade de Brasília (UnB). Horizontes Antropológicos, vol. 11, n. 23, Porto Alegre, 2005.

MAIO, Marcos Chor; SANTOS, Ricardo Ventura. As cotas raciais nos horizontes da antropologia: tréplica a dezoito comentaristas. Horizontes Antropológicos, vol. 11, n. 23, Porto Alegre, 2005b.

MOEHLECKE, Sabrina. Ação afirmativa: história e debates no Brasil. Cadernos de Pesquisa, São Paulo, n. 117, nov. 2002.

NOGUEIRA, Oracy. Preconceito racial de marca e preconceito racial de origem: sugestões de um quadro de referência para a interpretação do material sobre relações raciais no Brasil. Revista Tempo Social, v. 19, n. 1, São Paulo, 2006.

RAMOS, Jair de Souza. Dos males que vem com o sangue: as representações raciais e a categoria do imigrante indesejável nas concepções sobre imigração da década de 1920. In: MAIO, Marcos Chor; SANTOS, Ricardo Ventura (Org.). Raça, Ciência e Sociedade. Rio de Janeiro: Fiocruz/CCBB, 1996.

RIO DE JANEIRO. Lei n. 3708, de 9 de novembro de 2001. Institui cota de até $40 \%$ (quarenta por cento) para as populações negra e parda no acesso à Universidade do Estado do Rio de Janeiro e à Universidade Estadual do Norte Fluminense, e dá outras providências. Rio de Janeiro: Asssembleia Legislativa, 2001.

SEGATO, Rita Laura. Em memória de tempos melhores: os antropólogos e a luta pelo direito. Horizontes Antropológicos, vol. 11, n. 23, Porto Alegre, 2005.

SEGATO, Rita Laura. Cotas: por que reagimos? Revista USP, São Paulo, v. 1, n. 68, 2006. 
TEIXEIRA, Sérgio Alves; STEIL, Carlos Alberto. Introdução ao debate sobre cotas. Horizontes Antropológicos, vol. 11, n. 23, Porto Alegre, 2005.

VALENTE, Ana Lúcia E. F. A "má vontade antropológica" e as cotas para negros nas universidades (ou os usos e abusos da antropologia na pesquisa educacional II: quando os antropólogos desaprendem). Revista InterMeio, PPGE, Campo Grande, v. 12, n. 24, jul-dez. 2006.

\section{Fontes:}

ANDIFES. Cotas raciais, um erro. Na mídia. 27 de abril de 2012. Acesso em: 23/11/2018. Disponível em: <http://www.andifes.org.br/cotas-raciais-um-erro/>. 